\title{
Tau Loss Attenuates Neuronal Network Hyperexcitability in Mouse and Drosophila Genetic Models of Epilepsy
}

\author{
Jerrah K. Holth,,${ }^{1,2}$ Valerie C. Bomben, ${ }^{1}$ J. Graham Reed, ${ }^{1}$ Taeko Inoue, ${ }^{3}$ Linda Younkin, ${ }^{5}$ Steven G. Younkin, ${ }^{5}$ \\ Robia G. Pautler, ${ }^{3,4}$ Juan Botas, ${ }^{2}$ and Jeffrey L. Noebels ${ }^{1,2,4}$ \\ ${ }^{1}$ Developmental Neurogenetics Laboratory, Department of Neurology, and Departments of ${ }^{2}$ Molecular and Human Genetics, ${ }^{3}$ Molecular Physiology and \\ Biophysics, and ${ }^{4}$ Neuroscience, Baylor College of Medicine, Houston, Texas 77030, and ${ }^{5}$ Department of Neuroscience, Mayo Clinic, Jacksonville, Florida \\ 32224
}

Neuronal network hyperexcitability underlies the pathogenesis of seizures and is a component of some degenerative neurological disorders such as Alzheimer's disease (AD). Recently, the microtubule-binding protein tau has been implicated in the regulation of network synchronization. Genetic removal of Mapt, the gene encoding tau, in AD models overexpressing amyloid- $\beta(\mathrm{A} \beta)$ decreases hyperexcitability and normalizes the excitation/inhibition imbalance. Whether this effect of tau removal is specific to $A \beta$ mouse models remains to be determined. Here, we examined tau as an excitability modifier in the non-AD nervous system using genetic deletion of tau in mouse and Drosophila models of hyperexcitability. Kcna1 ${ }^{-1-}$ mice lack Kv1.1-delayed rectifier currents and exhibit severe spontaneous seizures, early lethality, and megencephaly. Young $\mathrm{Kcna1}^{-1-}$ mice retained wild-type levels of A $\beta$, tau, and tau phospho-Thr ${ }^{231}$. Decreasing tau in $\mathrm{Kcnal}^{-1-}$ mice reduced hyperexcitability and alleviated seizure-related comorbidities. Tau reduction decreased Kcna1 ${ }^{-1-}$ videoEEG recorded seizure frequency and duration as well as normalized Kcna1 ${ }^{-1-}$ hippocampal network hyperexcitability in vitro. Additionally, tau reduction increased $\mathrm{KCna1}^{-1-}$ survival and prevented megencephaly and hippocampal hypertrophy, as determined by MRI. Bang-sensitive Drosophila mutants display paralysis and seizures in response to mechanical stimulation, providing a complementary excitability assay for epistatic interactions. We found that tau reduction significantly decreased seizure sensitivity in two independent bang-sensitive mutant models, $k c c$ and eas. Our results indicate that tau plays a general role in regulating intrinsic neuronal network hyperexcitability independently of $\mathrm{A} \beta$ overexpression and suggest that reducing tau function could be a viable target for therapeutic intervention in seizure disorders and antiepileptogenesis.

\section{Introduction}

The microtubule-binding protein tau is implicated in cytoskeletal and intracellular trafficking functions including microtubule stability, transport, and signal transduction (Dixit et al., 2008; Wang and Liu, 2008; Ittner et al., 2010). This multifaceted protein figures prominently in the pathogenesis of neurodegenerative disorders such as Alzheimer's disease (AD) and frontotemporal dementia, where abnormally phosphorylated tau proteins aggregate to form neurofibrillary tangles (Goedert and Spillantini, 2006; Morris et al., 2011).

Although the underlying molecular mechanisms are unclear, recent studies have implicated tau in the regulation of excitability

\footnotetext{
Received July 5, 2012; revised Nov. 21, 2012; accepted Nov. 27, 2012.

Author contributions: J.K.H., V.C.B., S.G.Y., R.G.P., J.B., and J.L.N. designed research; J.K.H., V.C.B., J.G.R., T.I., and L.Y. performed research; J.K.H., V.C.B., L.Y., S.G.Y., J.B., and J.L.N. analyzed data; J.K.H., V.C.B., T.I., and J.L.N. wrote the paper.

This work was supported by the Epilepsy Foundation Predoctoral Fellowship (J.K.H.), NIH Grants R01NS29709 (J.L.N.), P01 AG022074 (J.L.N., PI: L. Mucke), NS042179 (J.B.), R01AG029977 (R.G.P.), P30DK079638 (B.C.M., Diabetes and Endocrinology Research (enter, MRI Core), NIA06656 (S.Y.), and the Blue Bird Circle Foundation. We thank Mark Tanouye and Daniel St. Johnston for supplying the Drosophila strains used in this study; and Joanna Jankowski for her assistance with amyloid analysis.

The authors declare no competing financial interests.

Correspondence should be addressed to Jeffrey L. Noebels, Department of Neurology, One Baylor Plaza, NB220, Houston, TX 77030. E-mail: jnoebels@bcm.edu.

DOI:10.1523/JNEUROSCI.3191-12.2013

Copyright $\odot 2013$ the authors $\quad 0270-6474 / 13 / 331651-09 \$ 15.00 / 0$
}

and synchronization of neuronal networks in AD mouse models. Genetic removal of tau decreases interictal spiking and spontaneous seizures in the J20 human amyloid precursor protein (hAPP) $\mathrm{AD}$ mouse, which overexpresses amyloid- $\beta$ (A $\beta$ ) (Roberson et al., 2011). In this model, tau knockout normalizes the inhibitory/ excitatory imbalance and rescues both the early lethality and cognitive dysfunction (Roberson et al., 2007, 2011). Tau protein is also linked to $\mathrm{A} \beta$-induced axonal transport deficits and synaptic long term potentiation alterations in hAPP AD mice, both of which are rescued by tau knockout (Vossel et al., 2010; Shipton et al., 2011). Expression of ApoE4, an AD risk factor allele, in mice also leads to network hyperexcitability (Hunter et al., 2012). ApoE4 mice exhibit GABAergic interneuron loss accompanied by learning and memory deficits due to high levels of toxic hyperphosphorylated tau that are rescued by tau reduction (Li et al., 2009; Andrews-Zwilling et al., 2010).

While the interaction between tau and network excitability is robust in $\mathrm{AD}$ models with $\mathrm{A} \beta$ or tau pathology, the ability of tau to modulate neuronal excitability in models without aberrant amyloid expression or tau hyperphosphorylation remains unknown. Tau knock-out mice themselves show decreased seizure severity following activation by convulsants (Roberson et al., 2007; Ittner et al., 2010). If tau removal plays a more general role in limiting excessive network firing, the interaction could be a viable target for treatment of other central excitability disorders. 
To address this possibility, we examined the effect of genetically decreased tau expression in mouse and Drosophila ion channelopathy mutants. The $\mathrm{KCna1}^{-1-}$ mouse is a model of temporal lobe epilepsy bearing a null allele for the $\alpha$ subunit of the Kv1.1 voltage-gated potassium channel (Smart et al., 1998). Humans with loss-of-function mutations in this gene have hyperexcitability phenotypes including epilepsy, myokymia, and episodic ataxia (Adelman et al., 1995; Zuberi et al., 1999; Liguori et al., 2001). Kcnal ${ }^{-1-}$ mice exhibit severe spontaneous seizures beginning in the third week of life that are accompanied by early lethality and megencephaly, making this model a robust test for the effects of tau on hyperexcitability (Smart et al., 1998; Glasscock et al., 2007; Persson et al., 2007). Bang-sensitive (BS) Drosophila mutants display behavioral seizure susceptibility following mechanical stimulation that is characterized by a period of paralysis followed by seizure-like limbshaking movements. BS mutants represent a genetically tractable model system for evaluating modifiers of human seizure disorders (Pavlidis et al., 1994; Kuebler and Tanouye, 2000; Kuebler et al., 2001; Parker et al., 2011).

\section{Materials and Methods}

Animals. Double-mutant mice were produced carrying various combinations of Kcna 1 - and Tau - alleles. Kcna 1 - mice carry a null mutation in the Kcnal gene on chromosome 6 (Smart et al., 1998). Tau- mice contain a targeted knock-out mutation in the Mapt gene on chromosome 11 (Dawson et al., 2001). Heterozygous F1 mice (Kcnal ${ }^{+-} \mathrm{Tau}^{+-}{ }^{+-}$), derived by crossing heterozygous $\mathrm{Kcna1}^{-/+}$mice (Tac:N:NIHS-BC) with homozygous $\mathrm{Tau}^{-1-}(\mathrm{C} 57 \mathrm{BL} / 6)$ mice, were intercrossed to produce F2 double mutants of mixed Black Swiss (BlSw, Tac:N:NIHS-BC) and $\mathrm{C} 57 \mathrm{BL} / 6$ background. Mice of either sex were used for all experiments unless otherwise stated. Mice were housed at $22^{\circ} \mathrm{C}$ with a $12 \mathrm{~h}$ light/dark cycle and fed ad libitum. All procedures were performed in accordance with the guidelines of the National Institute of Health, as approved by the Animal Care and Use Committee of Baylor College of Medicine.

Genotyping. Genomic DNA was isolated from tail clips using DirectPCR Lysis Reagent (Viagen Biotech). Genotype was determined using PCR amplification for specific alleles as described previously for Kcna1(Smart et al., 1998) and Tau- (Dawson et al., 2001). PCR products were separated on a $1.5 \%$ agarose gel by electrophoresis.

In vivo video-electroencephalography recordings. Kcna1 ${ }^{-1-}$ mice bred with varying tau alleles $\left(\mathrm{Tau}^{+/+}, \mathrm{Tau}^{+/-}\right.$, and $\mathrm{Tau}^{-1-}$ ) were anesthetized by Avertin and surgically implanted with bilateral silver wire electrodes ( 0.005 inch diameter) attached to a microminiature connector. Electroencephalography (EEG) wires were inserted into the subdural space over the temporal cortex through cranial burr holes. Mice were allowed to recover for 24 or more hours before analysis. EEG and behavioral activity in freely moving mice were analyzed using simultaneous video-EEG monitoring (Haramonie software version 6.1c, Stellate Systems). All EEG signals were filtered using a $0.3 \mathrm{~Hz}$ high-pass filter, $70 \mathrm{~Hz}$ low-pass filter, and $60 \mathrm{~Hz}$ notch filter. Eight mice of each genotype were monitored at 4-6 weeks of age and were each evaluated for a total of 9 or more hours. Mice were recorded in one or more 3-9 h monitoring sessions over several days to mitigate the effect of seizure clustering. Seizure activity defined by EEG waveform and corresponding video-recorded behavior was quantified by visual inspection.

Hippocampal slice preparation and electrophysiology. Transverse hippocampal slices (300 $\mu \mathrm{m}$ thickness) from double-mutant mice of genotypes $\mathrm{Kcnal}^{+/+} \mathrm{Tau}^{+++}, \mathrm{Kcnal}^{+/+} \mathrm{Tau}^{-1-}, \mathrm{Kcnal}^{-1-} \mathrm{Tau}^{+/+}$, and $\mathrm{Kcna1}^{-1-} \mathrm{Tau}^{-1-}(6-11$ weeks old $)$ were prepared using a vibratome. Slices were sectioned in cutting solution containing (in mM) 100 sucrose, $30 \mathrm{NaCl}, 3 \mathrm{KCl}, 0.5 \mathrm{CaCl}_{2}, 28 \mathrm{NaHCO}_{3}, 7 \mathrm{MgCl}_{2}, 1.4 \mathrm{NaH}_{2} \mathrm{PO}_{4}$, and 11 D-glucose and were constantly gassed with $95 \% \mathrm{O}_{2} / 5 \% \mathrm{CO}_{2}$ to maintain a constant $\mathrm{pH}$ of 7.4. After incubation in artificial CSF (ACSF) at $32^{\circ} \mathrm{C}$ for $1 \mathrm{~h}$, slices were transferred into a submerged recording chamber for electrophysiological recordings. Brain slices were constantly perfused with ACSF containing (in mM) $125 \mathrm{NaCl}, 2.5 \mathrm{KCl}, 2 \mathrm{CaCl}_{2}, 25 \mathrm{NaHCO}_{3}$,
$1 \mathrm{MgCl}, 1.25 \mathrm{NaH}_{2} \mathrm{PO}_{4}$, and $11 \mathrm{D}$-glucose. Recording chamber temperature was controlled at $32-33^{\circ} \mathrm{C}$. Recording pipettes $(4-6 \mathrm{Mohm})$ were pulled from borosilicate glass and filled with $2 \mathrm{M} \mathrm{NaCl}$. CA3 pyramidal neurons have been previously shown to exhibit altered in vitro network excitability in $\mathrm{Kcna1}^{-1-}$ mice (Smart et al., 1998; Lopantsev et al., 2003; Glasscock et al., 2007). Therefore, field recordings were made from the CA3 pyramidal somata identified visually in the stratum pyramidale using a Getting Instruments Model 5A amplifier, digitized by a Digidata 1322A, and collected using Clampex (Molecular Devices). A low-pass filter was set at $5 \mathrm{kHz}$. Slices were perfused with ACSF containing $7.5 \mathrm{~mm}$ $\mathrm{KCl}$ (Glasscock et al., 2007) and began synchronously discharging within a period of 15-25 min. To calculate the burst frequency, slices were allowed to equilibrate to $7.5 \mathrm{~mm} \mathrm{KCl}$ for an additional 5-15 min and the burst frequency was then calculated over a 5 min period. The burst duration was defined as the interval between baseline crossings and analyzed as the average of 10 bursts per slice. Data analysis was performed using Clampfit (Molecular Devices) and Origin 7.5 (OriginLab).

Three-dimensional magnetic resonance imaging and brain volumetry. MRI of the brain was performed on 12-week-old male mice of genotypes $\mathrm{Kcnal}^{-1-} \mathrm{Tau}^{+/+}, \mathrm{Kcnal}^{-1-} \mathrm{Tau}^{-1-}, \mathrm{Kcnal}^{+/+} \mathrm{Tau}^{+/+}$, and $\mathrm{Kcnal}^{+/+}$ $\mathrm{Tau}^{-1-}(n=3)$. Mice were overdosed with isofluorane, placed in a $50 \mathrm{ml}$ conical tube, and all imaged identically within $1 \mathrm{~h}$. To mitigate postmortem delay, mice were cooled to $20^{\circ} \mathrm{C}$ during imaging. MRI images were obtained using a $9.4 \mathrm{~T}, 21 \mathrm{~cm}$ bore horizontal scanner with a $35 \mathrm{~mm}$ volume resonator (Bruker, BioSpin). The imaging parameters used to obtain three-dimensional (3D) rapid acquisition with relaxation enhancement (RARE) images of the mouse brain were as follows: TR = $2000 \mathrm{~ms}$; TE $=11.713 \mathrm{~ms}$; effective $\mathrm{TE}=46.85 \mathrm{~ms} ; \mathrm{FOV}=25 \mathrm{~mm}^{3}$; matrix $=256 \times 256 \times 164$; RARE Factor $=8$; number of averages $=5$; total scan time $=14 \mathrm{~h} 34 \mathrm{~m} 40 \mathrm{~s}$. Images were obtained using Paravision software version 4 (Bruker, BioSpin).

MRI images were analyzed while blinded to genotype using Amira 3.1 software (Visage Imaging). The hippocampal border was segmented manually in both coronal and sagittal planes and the hippocampus volume measurement for each mouse was computed as the average of the volumes in the two planes. The forebrain volume was segmented in the sagittal plane.

Fly stocks and behavioral testing. Drosophila melanogaster were maintained on standard media at $25-26^{\circ} \mathrm{C}$. The BS strains used were easily shocked (eas), which encodes an ethanolamine kinase, and kazachoc $(k c c)$, which encodes a $\mathrm{K}^{+} / \mathrm{Cl}^{-}$cotransporter, and were obtained from $\mathrm{M}$. Tanouye at University of California, Berkley, Berkley, CA (Pavlidis et al., 1994; Hekmat-Scafe et al., 2006). The BS alleles used in this study were $e a S^{P C 80}$ and $k c c^{D H S 1}$. Tau P-element $\left(\operatorname{tau}^{E P 3203}\right)$ and deficiency $(D f(3 R)$ MR22) alleles were obtained from Bloomington Stock Center and D. St. Johnston at University of Cambridge, Cambridge, UK, respectively (Doerflinger et al., 2003). Male and female $k c c$ flies and male eas flies were analyzed for bang sensitivity 1-2 d posteclosion and not exposed to $\mathrm{CO}_{2}$ within $2 \mathrm{~h}$ preceding testing. To test, $\leq 10$ flies were placed in a clean vial and allowed to rest for $30 \mathrm{~min}$. Flies were vortexed (VWR) at maximum strength for $10 \mathrm{~s}$ and visually monitored for the presence of paralysis and seizure in each fly.

Western blotting. Kcna1 ${ }^{-1-}$ and Kcnal ${ }^{+/+}$forebrain hemisphere samples (4.5 weeks old) were extracted and flash frozen in liquid nitrogen. Samples were homogenized on ice using a Tissue Tearor (VWR) in lysis buffer with phosphatase inhibitors (20 mM Tris, pH 7.5, $138 \mathrm{~mm} \mathrm{NaCl}, 3$ mм KCl, 1\% Tx-100, 1 mм EGTA, 2 mм EDTA, 1 mм Benzamidine, 5 $\mu \mathrm{g} / \mathrm{ml}$ Aprotinin, $5 \mu \mathrm{g} / \mathrm{ml}$ Leupeptin, $5 \mu \mathrm{g} / \mathrm{ml}$ Pepstatin A, 1 mM PMSF, $1 \mathrm{~mm}$ DTT, $50 \mathrm{~mm} \mathrm{NaF}, 1 \mathrm{~mm} \mathrm{Na} \mathrm{VO}_{4}$ ) and protein concentration determined by Pierce BCA Protein Assay Kit (Thermo Scientific). Twenty micrograms of protein were separated on $12 \%$ Tris-Glycine-SDS polyacrylamide gels (Thermo Scientific) and transferred to nitrocellulose membrane. Membranes were blocked overnight at $4^{\circ} \mathrm{C}$ in $5 \%$ milk in TBST, and incubated with primary antibodies including mouse anti-Tau (Tau-5, 1:1000, Millipore), rabbit anti-Tau phospho-Threonine 231 (Tau-pT231, 1:1000, Millipore), and mouse anti-GAPDH (6C5, 1:5000, Advanced ImmunoChemical) for $2 \mathrm{~h}$ at room temperature. Membranes were then rinsed in TBST and incubated with appropriate HRPconjugated secondary antibody, either donkey anti-mouse or goat anti- 
A

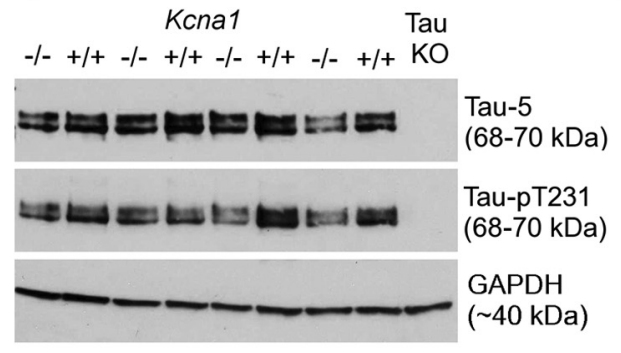

$\mathrm{B}$

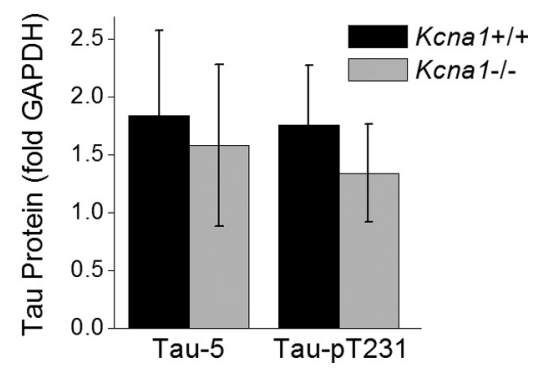

Figure 1. Tau protein levels and phosphorylation at $\mathrm{Thr}^{231}$ in 4.5-week-old Kcna ${ }^{-1-}$ mouse forebrain do not significantly differ from Kcna1 ${ }^{+/+}$mice. A, Representative Western blots of total tau (Tau-5), tau phospo-Thr ${ }^{231}$ (Tau-pT231), and GAPDHloading control for Kcna1 ${ }^{-1-}$ and $K c n a 1^{+1+}$ mice, as well as a tau knock-out, which showed no tau or tau phospho-Thr ${ }^{231}$ staining. B, Quantification of Tau-5 and Tau-pT231 normalized to GAPDH showed no significant difference in total tau or tau phospho-Thr ${ }^{231}$ levels between $K c n a 1^{-/-}$and $K c n a 1^{+/+}$mice. $p>0.05$; one-way ANOVA; $n=8$; error bars represent SD.

rabbit (1:10,000, Santa Cruz Biotechnology), for $1 \mathrm{~h}$ at room temperature. Protein was detected using SuperSignal chemiluminescent substrate (Pierce Thermo Scientific) and quantified by ImageJ (NIH). Membranes were stained sequentially for Tau- 5 and GAPDH, stripped in stripping buffer (2\% SDS, $100 \mathrm{~mm} \beta$-mercaptoethanol, $50 \mathrm{~mm}$ Tris, $\mathrm{pH}$ $6.8)$ at $50^{\circ} \mathrm{C}$ for $30 \mathrm{~min}$, and stained for Tau-pT231. Results were replicated three times to ensure accuracy.

$A \beta$ ELISA. Forebrain hemispheres were sonicated in $0.2 \%$ diethylamine (DEA) in $50 \mathrm{~mm} \mathrm{NaCl}$ with protease inhibitor (Sigma) at a volume of $1 \mathrm{ml}$ per $100 \mathrm{mg}$ of tissue. Samples were spun at 100,000 $\times g(53,000$ $\mathrm{rpm}$ ) for $30 \mathrm{~min}$ at $4^{\circ} \mathrm{C}$ and supernatant collected, neutralized in $0.5 \mathrm{M}$ Tris- $\mathrm{HCl}, \mathrm{pH} 6.8$, and analyzed by ELISA as previously described (Kawarabayashi et al., 2001). The pellet was then sonicated in $70 \%$ formic acid, centrifuged, and supernatant analyzed by ELISA. Mouse A $\beta$ levels were analyzed in $\mathrm{Kcnal}^{-1-}$ and $\mathrm{Kcnal}^{+/+}$mice using capture antibody BNT77, which specifically recognized rodent $A \beta 11-28$, and BA27 and $\mathrm{BC} 05$ antibodies to detect $\mathrm{A} \beta_{40}$ and $\mathrm{A} \beta_{42}$, respectively.

Statistical analysis. Data were analyzed for statistical significance using SPSS 16.0 (IBM). Survival analysis was completed by Kaplan-Meier log rank (Mantel-Cox). One-way ANOVA, with Tukey post hoc when necessary, was used to compare tau protein expression, abnormal EEG discharge duration, hippocampal volume, and forebrain volume between genotypes. Comparisons of seizure frequency between genotypes were made using the nonparametric Kruskal-Wallis test. Electrophysiology data were analyzed by one-way ANOVA with Bonferroni post hoc and A $\beta$ level comparisons made by $t$ test (two-tailed) using GraphPad Prism 5.0 (Graphpad Software). All analysis of Drosophila results was completed by $\chi^{2}$ analysis. Error bars represent SD unless otherwise stated with the exception of in vitro electrophysiology results, which are reported as SEM.

\section{Results}

Young Kv1.1-deficient mice maintain wild-type A $\beta$, tau, and tau phospho-Thr ${ }^{231}$ protein levels in the forebrain

Since electrically induced seizures are known to acutely stimulate $\mathrm{A} \beta$ secretion, and kainic acid injections induce tau phosphorylation in mice, we first evaluated the $\mathrm{Kcnal}^{-1-}$ brain for evidence of AD-like molecular pathology (Cirrito et al., 2005; Crespo-Biel et al., 2007; Liang et al., 2009). To determine whether chronic spontaneous seizures in young Kcnal ${ }^{-1-}$ mice alter $\mathrm{A} \beta$ levels or tau levels and phosphorylation, 4.5-week-old $\mathrm{Kcna1}^{-1-}$ and $\mathrm{Kcna1}^{+/+}(n=8)$ littermate mouse forebrain samples were analyzed by ELISA for $\mathrm{A} \beta_{40}$ and $\mathrm{A} \beta_{42}$ as well as Western blot for total tau (Tau-5) and tau phosphorylated at threonine 231 (TaupT231). ELISA analysis showed that soluble, DEA-extracted $\mathrm{A} \beta_{40}, \mathrm{~A} \beta_{42}$, and total $\mathrm{A} \beta$ levels in young $\mathrm{KCna1}^{-1-}$ mice were not significantly different from Kcnal ${ }^{+/+}$wild-type controls $\left(\mathrm{A} \beta_{40}\right.$ : Kcnal $^{-/-}: 108.44 \pm 8.26 \mathrm{pmol}$ Kcnal $^{+/+}: 96.91 \pm 14.84 \mathrm{pmol}$, $p=0.08 ; \mathrm{A} \beta_{42}:$ Kcnal $^{-1-}: 27.07 \pm 3.05$ pmol, Kcnal ${ }^{+/+}: 24.28 \pm 3.60$ pmol, $p=$ 0.12 ; total A $\beta:$ Kcnal $^{-/-}: 135.51 \pm 11.22$ pmol, Kcnal ${ }^{+/+}$: $121.19 \pm 18.37$ pmol, $p=0.08, n=8)$. There was also no difference in the ratio of $\mathrm{A} \beta_{40} / \mathrm{A} \beta_{42}$ between $\mathrm{Kcnal}^{-/-}$and wild-type mice (Kcnal ${ }^{-/-}$: $4.02 \pm 0.18$, Kcnal $^{+/+}: 3.99 \pm 0.13, p=$ $0.69, n=8)$. No aggregated $\mathrm{A} \beta$ was detected in formic acid isolated samples from mice of either genotype.

Next, we analyzed Tau levels and phosphorylation at threonine 231. We selected this phosphorylation site since $\mathrm{Thr}^{231}$ phosphorylation is increased within $3 \mathrm{~d}$ after kainic acid-induced status epilepticus in mice, but the effect of spontaneous seizures on this site is not currently known (Crespo-Biel et al., 2007). Additionally, tau phosphorylation at $\mathrm{Thr}^{231}$ occurs early in the pre-NFT stage of human AD pathogenesis, and a high level of tau phospho-Thr ${ }^{231}$ in patients with mild cognitive impairment correlates with subsequent development of AD (Augustinack et al., 2002; Buerger et al., 2002), making it an informative biomarker to test for early changes in tau phosphorylation status in young Kv1.1-null mice. Western blot analysis (Fig. 1A) showed that $\mathrm{Kcnal}^{-/-}$total tau and tau phospho$\mathrm{Thr}^{231}$ levels, normalized to GAPDH, were not significantly different from those in wild-type Kcnal ${ }^{+/+}$mice (Fig. $1 B$; Tau-5: Kcnal $^{+/+}: 1.84 \pm 0.74$, Kcnal $^{-/-}: 1.58 \pm 0.70, p=0.49$; TaupT231: Kcnal $^{+/+}: 1.76 \pm 0.52$, Kcnal $^{-/-}: 1.34 \pm 0.42, p=0.10$, $n=8)$. The ratio of tau phospho-Thr ${ }^{231}$ to total tau also did not significantly differ between $\mathrm{Kcnal}^{-/-}$and $\mathrm{Kcnal}^{+/+}$mice $\left(\right.$ Kcnal $^{+/+}: 1.06 \pm 0.32$, Kcnal $\left.^{-/-}: 0.92 \pm 0.23, p=0.33, n=8\right)$. These results demonstrate that hyperexcitability and spontaneous epileptic seizures in the forebrain of young Kv1.1-null mice do not appreciably affect $A \beta$ and tau levels, or induce sustained abnormal tau phosphorylation at $\mathrm{Thr}^{231}$. Thus, young Kcna1 ${ }^{-/-}$ mice do not display signs of AD-like molecular pathology despite the occurrence of spontaneous seizures.

\section{Decreasing tau reduces hyperexcitability in Kv1.1- deficient mice}

To determine whether tau loss affects hyperexcitability and spontaneous seizures we recorded $\mathrm{KCnal}^{-/-}$Tau double-mutant male and female mice (4-6 weeks old) with in vivo video-EEG for 9 or more hours. Electrocorticograms of $\mathrm{KCna1}^{-/-}$mice showed frequent and severe spontaneous seizures characterized by abnormal, generalized, high-frequency hypersynchronous EEG discharges (200-500 mV amplitude) with abrupt cessation, followed by a period of EEG amplitude depression (Fig. 2A). Seizures in $\mathrm{Kcna1}^{-/-}$ mice occurred up to 1.27 times an hour with an average of $0.51 \pm$ 0.19 seizures/h (Fig. $2 B$; \pm SEM). Decreasing tau by heterozygous and homozygous tau knock out significantly decreased seizure frequency in $\mathrm{Kcnal}^{-/-}$mice to 0 and $0.03 \pm 0.03$ seizures/h, respectively (Fig. 2B; \pm SEM; Kcnal ${ }^{-1-} \mathrm{Tau}^{+/+}$vs Kcnal $^{-1-} \mathrm{Tau}^{+/-}: \mathrm{p}=$ $0.011 ; \mathrm{Kcnal}^{-1-} \mathrm{Tau}^{+/+}$vs $\left.\mathrm{Kcnal}^{-1-} \mathrm{Tau}^{-1-}: p=0.035, n=8\right)$. None of the $8 \mathrm{Kcna1}^{-1-} \mathrm{Tau}^{+/-}$mice and only 1 of $8 \mathrm{Kcnal}^{-1-}$ $\mathrm{Tau}^{-1-}$ mice displayed seizures during recording, compared with 5 of $8 \mathrm{Kcnal}^{-1-} \mathrm{Tau}^{+/+}$mice (Fig. $2 \mathrm{~B}$ ). Individual $\mathrm{Kcnal}^{-1-} \mathrm{Tau}^{+/+}$ mice showed a variable range of seizure frequency that was not due to sex or litter. The range was most likely due to phenotypic variation of the Kcnal ${ }^{-/-}$model within a mixed background $(\mathrm{C} 57 \mathrm{BL} / 6 / \mathrm{BlSw})$. Importantly, this variability was not 
A

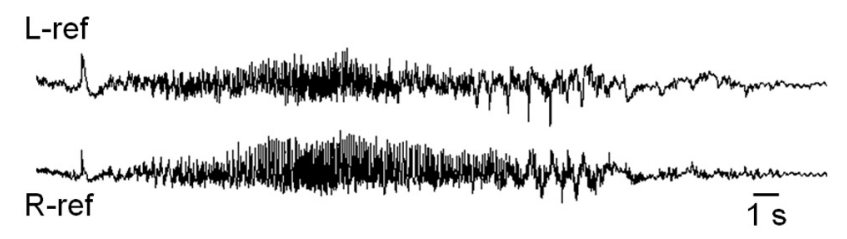

$\mathrm{B}$

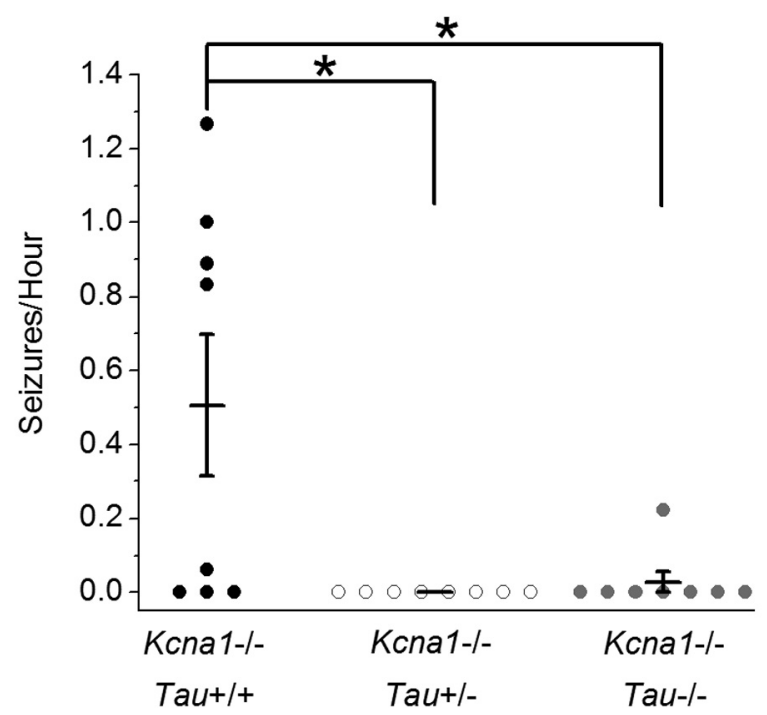

Figure 2. Tau reduction significantly decreases seizure frequency in $\mathrm{Knal}^{-1-}$ mice. $\mathrm{A}$, Representative spontaneous cortical seizure recorded bilaterally in a $\mathrm{Knna}^{-1-}$ mouse during chronic in vivo EEG monitoring. $\boldsymbol{B}$, Analysis of seizures/ $h$ in double-mutant mice recorded for 9 or more hours. Both tau reduction and loss significantly decreased seizure frequency in $\mathrm{Knal}^{-1-} \mathrm{Tau}^{+1-}(n=8)$ and $\mathrm{Knal}^{-1-} \mathrm{Tau}^{-1-}(n=8)$ double mutants compared with $\mathrm{Knal}^{-1-} \mathrm{Tau}^{+/+}(n=8)$. Seizures were observed in $5 / 8 \mathrm{Knal}^{-1-} \mathrm{Tau}^{+/+}$mice, $0 / 8 \mathrm{Knal}^{-1-} \mathrm{Tau}^{+/-}$mice, and only $1 / 8$ $\mathrm{KCna1}^{-1-} \mathrm{Tau}^{-1-}$ mice. Total deletion of tau reduced the average seizure frequency by $>94 \%$. ${ }^{*} p<0.05$; Kruskal-Wallis; error bars represent SEM.

observed in $\mathrm{KCnal}^{-1-} \mathrm{Tau}^{+/-}$or $\mathrm{KCnal}^{-1-} \mathrm{Tau}^{-1-}$ mice, which both had significantly decreased seizure frequency compared with Kcnal $^{-1-}$ Tau $^{+/+}$.

In addition to decreasing the number of behavioral seizures in $\mathrm{Kcna1}^{-1-}$ mice, tau loss also significantly decreased the duration of abnormal electrographic cortical discharge activity by $\sim 60 \%$. This measure includes $\mathrm{Kcnal}^{-1-}$ seizures (Fig. $2 \mathrm{~A}$ ) as well as abnormal spike bursts that consist of repetitive, distinct spikes, and/or spike-wave complexes occurring at a maximum frequency of 3-9 Hz. These aberrant electrographic discharges in $\mathrm{Kcnal}^{-1-} \mathrm{Tau}^{+/+}$mice averaged $43 \pm 32 \mathrm{~s}$ in duration $(n=54)$ compared with $\mathrm{Kcnal}^{-1-} \mathrm{Tau}^{-1-}$ mice, which averaged only $18 \pm 8 \mathrm{~s}(n=11, p=0.013)$. Together, these results demonstrate that decreasing tau dosage, even to heterozygous levels, can decrease cortical hyperexcitability in $\mathrm{KCnal}^{-1-}$ seizure mutants.

$\mathrm{Kcna1}^{-1-}$ mice have altered in vitro network excitability in the CA3 pyramidal region of the hippocampus when exposed to elevated potassium levels (Smart et al., 1998; Lopantsev et al., 2003; Glasscock et al., 2007). To further examine the effect of tau loss on hyperexcitability, we analyzed in vitro hippocampal network excitability in the CA3 pyramidal region of Kcna1Tau double mutants. When extracellular $\mathrm{K}^{+}$was raised from $2.5 \mathrm{~mm}$ to $7.5 \mathrm{~mm}$, we observed spontaneous discharges that stabilized at frequencies after 5-15 min in all slices, but frequency and duration of bursts varied by genotype. Kcnal ${ }^{-1-} \mathrm{Tau}^{+/+}$burst, on average, almost three times faster than $\mathrm{Kcnal}^{+/+} \mathrm{Tau}^{+/+}$wild-type con- trols (Fig. $3 A, B ; \mathrm{Kcnal}^{-/-} \mathrm{Tau}^{+/+}: 0.52 \pm 0.04 \mathrm{~Hz}, n=22$, Kcnal $\left.^{+/+} \mathrm{Tau}^{+/+}: 0.17 \pm 0.02 \mathrm{~Hz}, n=17, p<0.0001\right)$. Conversely, burst duration was significantly decreased in $\mathrm{Kcnal}^{-1-}$ $\mathrm{Tau}^{+/+}$mice compared with $\mathrm{Kcnal}^{+/+} \mathrm{Tau}^{+/+}$controls (Fig. $3 C, D ;$ Kcnal $^{-/-} \mathrm{Tau}^{+/+}: 94.4 \pm 5.0 \mathrm{~ms}, n=22, \mathrm{Kcnal}^{+/+} \mathrm{Tau}^{+/+}$: $118.6 \pm 5.4 \mathrm{~ms}, n=17, p<0.05)$.

Tau loss significantly decreased burst frequency in $\mathrm{Kcna1}^{-/-}$ mice and $\mathrm{Kcnal}^{-1-} \mathrm{Tau}^{-1-}$ mice were not significantly different from $\mathrm{KCnal}^{+/+} \mathrm{Tau}^{+/+}$controls. Tau loss in $\mathrm{Kcnal}^{-1-}$ mice reduced burst frequency to wild-type levels (Fig. $3 A, B$; Kcnal ${ }^{-1-}$ $\mathrm{Tau}^{-1-}: 0.26 \pm 0.03 \mathrm{~Hz}, n=19$, vs $\mathrm{Kcnal}^{-1-} \mathrm{Tau}^{+/+}: p<$ 0.0001 , vs Kcnal $\left.{ }^{+/+} \mathrm{Tau}^{+/+}: p>0.05\right)$. Interestingly, tau loss did not alter burst frequency in wild-type slices (Fig. $3 \mathrm{~A}, \mathrm{~B} ; \mathrm{Kcnal}^{+/+}$ $\mathrm{Tau}^{-1-}: 0.18 \pm 0.02 \mathrm{~Hz}, n=15$, vs $\mathrm{Kcnal}^{+/+} \mathrm{Tau}^{+/+}: p>0.05$, vs $\left.\mathrm{Kcna1}^{-1-} \mathrm{Tau}^{-1-}: p>0.05\right)$. Similarly, burst duration in $\mathrm{Kcnal}^{-1-} \mathrm{Tau}^{-1-}$ mice is significantly increased compared with $\mathrm{KCnal}^{-/-} \mathrm{Tau}^{+/+}$and not significantly different from Kcnal ${ }^{+/+}$ $\mathrm{Tau}^{+/+}$controls. Loss of tau rescued burst duration in $\mathrm{Kcnal}^{-1-}$ mice to wild-type levels (Fig. 3C,D; $\mathrm{Kcnal}^{-1-} \mathrm{Tau}^{-1-}: 134.8 \pm$ $8.1 \mathrm{~ms}, n=19$, vs $\mathrm{Kcnal}^{-1-} \mathrm{Tau}^{+/+}: p<0.0001$, vs $\mathrm{Kcnal}^{+/+}$ $\left.\mathrm{Tau}^{+/+}: p>0.05\right) . \mathrm{Kcnal}^{+/+} \mathrm{Tau}^{-/-}$burst duration was also not significantly different from $\mathrm{KCnal}^{+/+} \mathrm{Tau}^{+/+}$controls or Kcnal $^{-l-}$ Tau $^{-l-}$ mice (Fig. 3C,D; Kcnal ${ }^{+1+}$ Tau $^{-1-}: 123.8 \pm 5.8$ ms, $n=15$, vs Kcnal ${ }^{+/+}$Tau $^{+/+}: p>0.05$, vs Kcnal ${ }^{-1-}$ Tau $^{-1-}$ : $p>0.05)$. These results demonstrate that tau loss can prevent in vitro hippocampal network hyperexcitability in the epileptic Kcnal ${ }^{-l-}$ brain, but does not alter wild-type hippocampal excitability.

\section{Decreasing tau dosage increases survival in Kv1.1- deficient mice}

Kv1.1-null mice die prematurely and are an established model of sudden unexpected death in epilepsy (SUDEP) (Glasscock et al., 2010, 2012). Since tau loss in Kcnal ${ }^{-1-}$ mice decreased cortical hyperexcitability and seizures, we examined whether tau loss could prolong lifespan in $\mathrm{KCna1}^{-/-}$mice by daily monitoring of $\mathrm{Kcna1}^{-/-}$Tau double-mutant survival. Kcnal ${ }^{-1-} \mathrm{Tau}^{+/+}$mice $(n=27)$ died prematurely beginning in the third week of life with only $30 \%$ surviving to 10 weeks (Fig. 4). However, when tau dosage is decreased by heterozygous tau deletion, $\mathrm{KCna1}^{-/-} \mathrm{Tau}^{+/-}$ mice $(n=37)$ had a significant twofold increase in survival, with $59 \%$ alive at 10 weeks of age (Fig. $4 ; p=0.013$ ). $\mathrm{Kcnal}^{-/-} \mathrm{Tau}^{-/-}$ mice $(n=23)$ exhibited an even more striking decrease in mortality rate, with $74 \%$ surviving until 10 weeks (Fig. $4 ; p=0.003$ ). This increase in survival was also demonstrated in video-EEG monitoring studies, where episodes of status epilepticus followed by death were observed in $\mathrm{KCnal}^{-/-} \mathrm{Tau}^{+/+}$and $\mathrm{KCnal}^{-1-} \mathrm{Tau}^{+/-}$ mice but not $\mathrm{KCnal}^{-1-} \mathrm{Tau}^{-1-}$ mice while undergoing video-EEG recording. These results support a robust role for tau loss in suppressing central hyperexcitability, and demonstrate the positive effect of decreasing tau dosage, even by $50 \%$, on seizures and premature lethality.

\section{Tau loss prevents megencephaly in Kv1.1-deficient mice}

In addition to seizures and early lethality, $\mathrm{Kcnal}^{-1-}$ mice exhibit abnormal enlargement of the hippocampus and ventral cortex (Persson et al., 2007). To determine whether tau loss can influence megencephaly in Kcna1 ${ }^{-1-}$ mice, double-mutant mouse brains were imaged by MRI and analyzed for total hippocampal and forebrain volume (Fig. 5). At 12 weeks of age, Kcnal $^{-1-}$ mice had noticeably larger hippocampal and forebrain volumes that were significantly increased relative to $\mathrm{KCnal}^{+/+} \mathrm{Tau}^{+/+}$controls by 43.3 and $33.1 \%$, respectively (Fig. 5Q,R; hippocampus: 
A

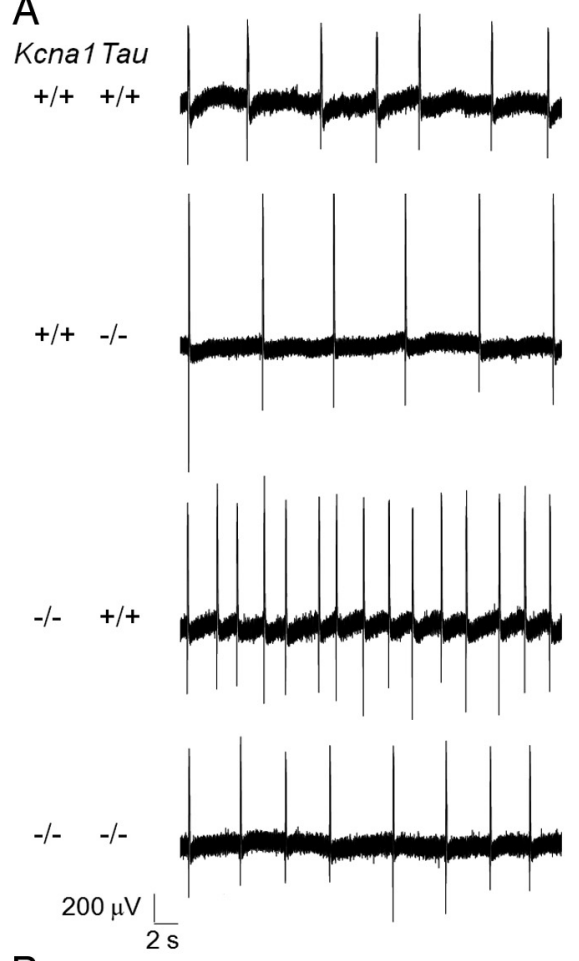

B

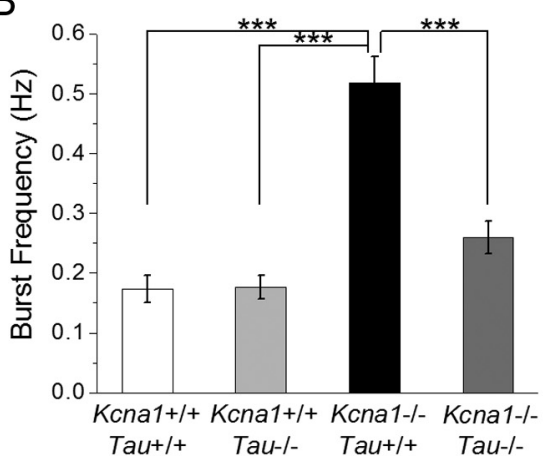

C Kena1 Tau $+/++/+$

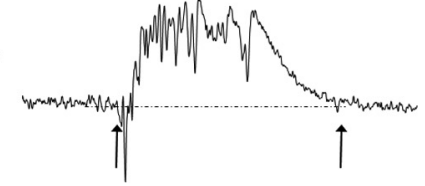

$+/+-/-$
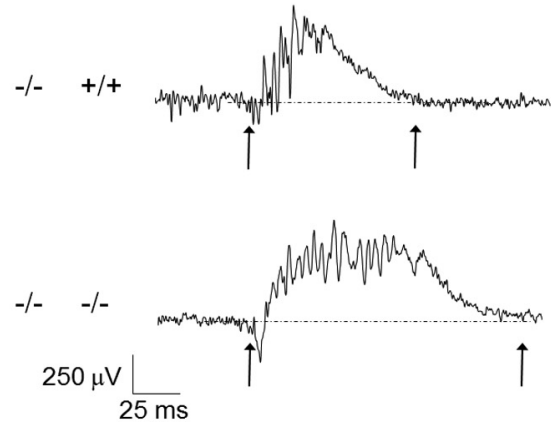

$\mathrm{D}$

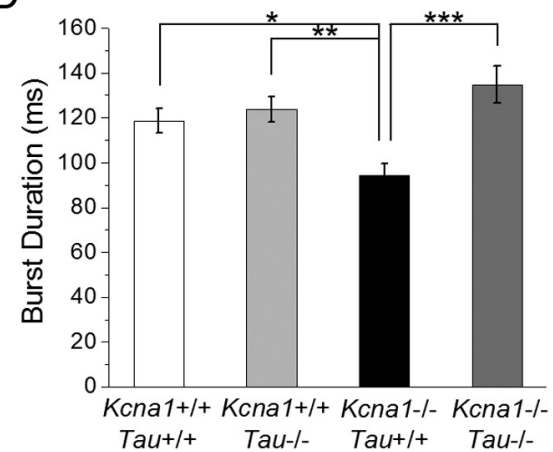

$\mathrm{Kcnal}^{-/-} \mathrm{Tau}^{-1-}$ vs $\mathrm{Kcnal}^{+/+} \mathrm{Tau}^{-/-}$: p $=0.49 ; \mathrm{Kcnal}^{-/-} \mathrm{Tau}^{-/-}$vs $\mathrm{Kcnal}^{+/+}$ Tau $^{+/+}: p=0.93, n=3$ ). Loss of tau rescued $\mathrm{Kcnal}^{-1-}$ megencephaly and decreased brain volume to wild-type levels. This observed decrease in volume was not due to tau loss alone, since hippocampal and forebrain volumes in $\mathrm{KCnal}^{+1+} \mathrm{Tau}^{-1-}$ mice did not differ from those of $\mathrm{Kcnal}^{+/+}$ $\mathrm{Tau}^{+/+}$wild-type controls (Fig. 5Q,R; $\mathrm{Kcnal}^{+/+} \mathrm{Tau}^{-l-}$ : hippocampus: $21.07 \pm$ $1.30 \mathrm{~mm}^{3}, p=0.91$; forebrain: $271.35 \pm$ $\left.10.87 \mathrm{~mm}^{3}, p=0.81, n=3\right)$. Light microscopic examination of cresyl violet-stained sections revealed that tau loss had no discernible neurocytological effects on regional brain structure or organization, including cortical or hippocampal lamination (data not shown). These findings suggest that tau loss not only decreases network hyperexcitability, but also prevents megencephaly associated with epilepsy in the Kv1.1 model.

\section{Reducing tau decreases}

hyperexcitability in bang-sensitive Drosophila mutants

BS Drosophila mutants define a class of functional excitability phenotypes that display behavioral seizure susceptibility following mechanical or electrical shock. Upon stimulation, these mutants exhibit intense activation (limbshaking) followed by a period of paralysis and a second period of hyperexcitability characterized by uncoordinated seizure-like movements (Pavlidis et al., 1994), and are an established model system for human seizure disorders (Kuebler and Tanouye, 2000; Kuebler et al., 2001; Song and Tanouye, 2008). To determine whether tau reduction is sufficient to decrease hyperexcitability in Drosophila BS mutants, double-mutant flies generated by decreasing tau gene expression in several different BS models were tested for paralysis and seizure phenotypes following $10 \mathrm{~s}$ of a vortex stimulus. Drosophila with homozygous tau deficiency are nonviable. Therefore, to reduce tau levels in Drosophila, two previously reported alleles were used. The first, a P-element disruption of the tau gene, tau $^{E P 3203}$, has a P-element insertion in the $\mathrm{Kcnal}^{-/-} \mathrm{Tau}^{+/+}: 31.65 \pm 1.42 \mathrm{~mm}^{3}, \mathrm{Kcnal}^{+/+} \mathrm{Tau}^{+/+}$: $22.08 \pm 2.48 \mathrm{~mm}^{3}, p=0.001$; forebrain: $\mathrm{Kcna1}^{-1-} \mathrm{Tau}^{+/+}$: $379.86 \pm 13.24 \mathrm{~mm}^{3}$, Kcnal $^{+/+}$Tau $^{+/+}: 285.38 \pm 27.64 \mathrm{~mm}^{3}$, $p=0.001, n=3)$. Removal of tau resulted in a significant decrease in both hippocampal and forebrain volume by 25.7 and $22.4 \%$, respectively, for $\mathrm{KCnal}^{-1-} \mathrm{Tau}^{-1-}$ mice compared with $\mathrm{KCnal}^{-1-} \mathrm{Tau}^{+/+}$ (Fig. 5Q,R; Kcna1 ${ }^{-1-} \mathrm{Tau}^{-1-}$ : hippocampus: $23.53 \pm 2.01 \mathrm{~mm}^{3}, p=$ 0.003; forebrain: $\left.294.59 \pm 20.88 \mathrm{~mm}^{3}, p=0.003, n=3\right)$. Kcnal ${ }^{-1-}$ $\mathrm{Tau}^{-1-}$ hippocampal and forebrain volumes did not differ from $\mathrm{KCnal}^{+/+} \mathrm{Tau}^{-/-}$or $\mathrm{KCnal}^{+/+} \mathrm{Tau}^{+/+}$controls (Fig. 5Q,R; hippocampus: $\mathrm{KCnal}^{-/-} \mathrm{Tau}^{-1-}$ vs $\mathrm{KCnal}^{+/+} \mathrm{Tau}^{-1-}: \mathrm{p}=0.43$; $\mathrm{Kcnal}^{-/-} \mathrm{Tau}^{-1-}$ vs $\mathrm{Kcnal}^{+/+} \mathrm{Tau}^{+/+}: \mathrm{p}=0.78$; forebrain: first intron of the gene (Doerflinger et al., 2003). The second is a tau deficiency allele, $D f(3 R) M R 22(M R 22)$, which has a $62 \mathrm{~kb}$ deletion caused by recombination of EP3203, removing most of the tau locus and resulting in homozygous lethality (Doerflinger et al., 2003).

Kcc BS Drosophila $\left(k_{c c}{ }^{D H S 1}\right)$ carry a partial loss-of-function mutation in the $\mathrm{K}^{+} / \mathrm{Cl}^{-}$cotransporter gene kazachoc (HekmatScafe et al., 2006). When tau was reduced in $k c c$ flies by tau ${ }^{E P 3203}$, the percentage of flies that exhibited bang-sensitive behavior and paralysis was significantly decreased by $40 \%$ with homozygous tau $^{E P 3203}$ and $34 \%$ with tau $^{E P 3203} /+$ (Fig. 6; $k c c ;+/+: 47 \%$ BS, $k c c ; t^{E u^{E P 3203}}: 28 \% \mathrm{BS}, k c c ; \operatorname{tau}^{E P 3203} /+: 31 \% \mathrm{BS}, k c c ;+/+$ vs $k c c$; tau $^{E P 3203}: p<0.01, k c c ;+/+$ vs $k c c ;$ tau $^{E P 3203} /+: p<0.05, \mathrm{n} \geq 87$ ). 


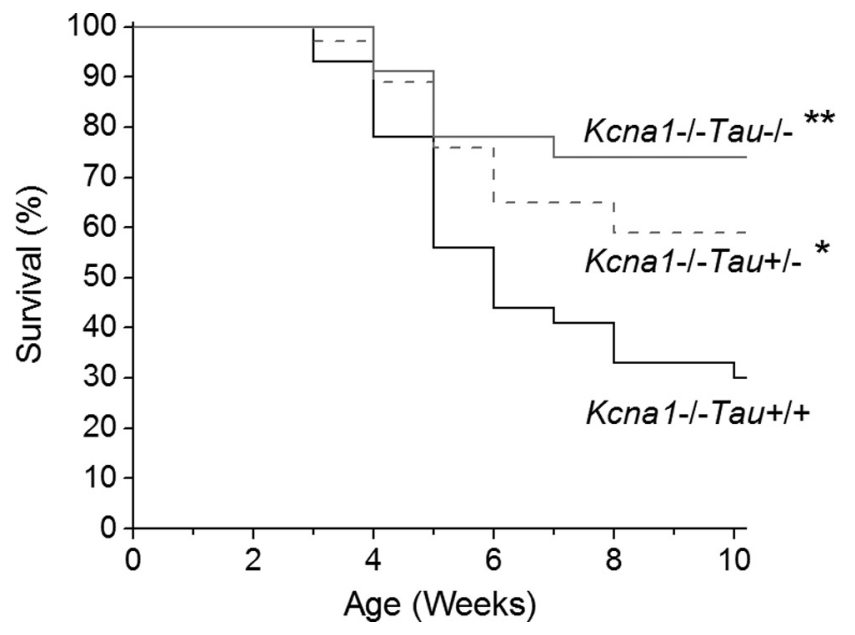

Figure 4. Decreasing tau dosage significantly increases survival of $\mathrm{Knal}^{-1-}$ mice. Kaplan-Meier survival curves show that $K \mathrm{cna}^{-1-}{ }^{-1 a u^{+/+}}$mice $(n=27)$ exhibited severe early lethality beginning in the third week of life, with only $30 \%$ surviving to 10 weeks of age. Decreasing tau dosage in $\mathrm{Knal}^{-1-}$ mice by heterozygous $(n=37)$ and homozygous $(n=23)$ tau knock-out significantly increased survival, with 59 and $74 \%$ survival, respectively, to 10 weeks of age. ${ }^{*} p=0.013,{ }^{* *} p=0.003$, all significant with respect to $\mathrm{Knal}^{-/-} \mathrm{Tau}^{+/+}$; Kaplan-Meier log rank test.

Additionally, we decreased tau levels in the more seizuresensitive eas mutant, which displays hyperexcitability due to reduced ethanolamine kinase activity, using the deficiency allele MR22 (Pavlidis et al., 1994; Doerflinger et al., 2003). Tau reduction by MR22 significantly decreased bang sensitivity in eas Drosophila by $13 \%$ in eas;MR22/+ and $15 \%$ in eas;MR22/ tau ${ }^{E P 3203}$ flies (Fig. 6; eas; +/+: 97\% BS, eas;MR22/+: 84\% BS, eas;MR22/ $\left.\operatorname{tau}^{E P 3203}: 82 \% \mathrm{BS}, p<0.001, n \geq 98\right)$. Tau reduction therefore decreased bang sensitivity in multiple Drosophila models, suggesting a broader role of tau in regulation of hyperexcitability due to a variety of molecular pathologies.

\section{Discussion}

The removal of tau and consequent suppression of epilepsy in $\mathrm{AD}$ mouse models established a critical epistatic role for tau in regulating cortical network excitability (Ittner et al., 2010; Roberson et al., 2011). Here, we demonstrate that the beneficial effects of tau loss on aberrant synchronization extend beyond the prevention of $\mathrm{A} \beta$-induced network excitability to encompass hyperexcitability phenotypes due to other, non-AD related causes. Genetic reduction of tau dosage, even to heterozygous levels, significantly decreased spontaneous seizure frequency and duration in the $\mathrm{Kcnal}^{-/-}$mouse model of temporal lobe epilepsy. Tau knock-out also decreased Kcna1 ${ }^{-/-}$hippocampal network hyperexcitability in response to elevated $\mathrm{K}^{+}$levels in vitro. In addition to attenuating hyperexcitability, tau loss decreased the early brain and vagal nerve-driven lethality in this model (Glasscock et al., 2010, 2012) and prevented Kv1.1-related megencephaly, with hippocampal and forebrain volumes decreased to wild-type levels. These findings demonstrate a robust and beneficial effect of tau removal on hyperexcitabilityrelated brain phenotypes in the absence of $\mathrm{AD}$-related molecular pathology. As further confirmation, we also found a decrease in experimentally evoked hyperexcitability behaviors in Drosophila kcc and eas BS mutants when tau levels were reduced, consistent with findings that tau loss decreases chemically evoked seizure severity in mice (Roberson et al., 2007; Ittner et al., 2010).
$\mathrm{A} \beta$, tau, and network excitability in young $\mathrm{Kcna1}^{-/-}$mice Hyperphosphorylation of tau at $\mathrm{Thr}^{231}$ is an early event in the progression of tau phosphorylation and NFT production in the human AD brain (Augustinack et al., 2002). Although only one of many tau phosphorylation sites, $\mathrm{Thr}^{231}$ phosphorylation is increased in response to kainic acid-induced seizures, and is thus a suitable indicator of tau phosphorylation in our spontaneous seizure mouse model (Crespo-Biel et al., 2007). Additionally, electrically induced synaptic activity and seizures stimulates $\mathrm{A} \beta$ secretion (Cirrito et al., 2005). Despite chronic spontaneous seizures, young $\mathrm{KCnal}^{-/-}$mice had no changes in forebrain A $\beta$ production or tau levels and phosphorylation at $\mathrm{Thr}^{231}$. Therefore, rescue of the $\mathrm{Kcnal}^{-/-}$hyperexcitability phenotype by tau loss in 4-6 week-old mice is unlikely due to prevention of a neurotoxic hyperphosphorylated tau species, as seen in $\mathrm{AD}$ ApoE4 knockin mice, but rather to a loss or reduction of an intrinsic molecular function of tau (Andrews-Zwilling et al., 2010). Transgenic hAPP mice, including the J20 model, also lack hyperphosphorylated tau yet are protected from hyperexcitability by tau loss, supporting the possibility that tau regulates excess excitability in developing or adult brain (Roberson et al., 2007, 2011; Ittner et al., 2010).

\section{Tau loss alleviates downstream seizure-induced comorbidities \\ Longevity}

Tau removal increases survival in two hAPP transgenic mouse strains as well as kainic acid injection seizure models (Roberson et al., 2007; Ittner et al., 2010; Roberson et al., 2011). Our results show that tau loss is similarly effective in a genetic model of epilepsy. Even heterozygous reduction of tau was sufficient to significantly increase survival in the $\mathrm{KCnal}^{-/-}$mutant, as it did in hAPP AD models. In contrast, tau deletion has no effect on survival of SOD1 mutants, a model of ALS with excitotoxic neurodegeneration, indicating that tau loss does not confer resistance to premature mortality in all neurological disorders (Roberson et al., 2011).

\section{Megencephaly}

A dramatic enlargement of the hippocampus and ventral cortex in $\mathrm{Kcnal}^{-/-}$BALB.C3HeB mice is detectable by 12 weeks of age (Persson et al., 2007). We confirmed this pathology in Kcnal ${ }^{-1-}$ mutants on a different genetic background (mixed C57BL/6/ BlSw), where we found a 43 and $33 \%$ increase in hippocampal and forebrain volume, respectively, compared with wild-type mice. Since the original megenchephaly (Mceph) mouse model containing a spontaneous Kcnal truncation mutation shows a comparable increase in brain volume, the megencephaly phenotype is likely caused by loss of Kcnal function (Persson et al., 2007). The Mceph mutation increases neuronal and astrocytic proliferation, leading to slow postnatal brain enlargement (Almgren et al., 2007; Yang et al., 2012). This hyperplasia can be suppressed by early treatment with the antiepileptic drug carbamazepine (Lavebratt et al., 2006). The mechanism linking impaired Kv1.1 current, seizures, and the multifactorial megencephaly phenotype has not been fully explored; however, recent findings indicate that Kv1.1 currents can play a cell autonomous role in precursor cell neurogenesis (Yang et al., 2012).

We found that tau loss prevented Kv1.1 megencephaly, with both hippocampal and forebrain volume decreased in 12-weekold $\mathrm{KCna1}^{-1-} \mathrm{Tau}^{-1-}$ mice to wild-type levels. This was not due to the simple absence of tau, since hippocampal and forebrain volume in pure tau knock-out mice were indistinguishable from 

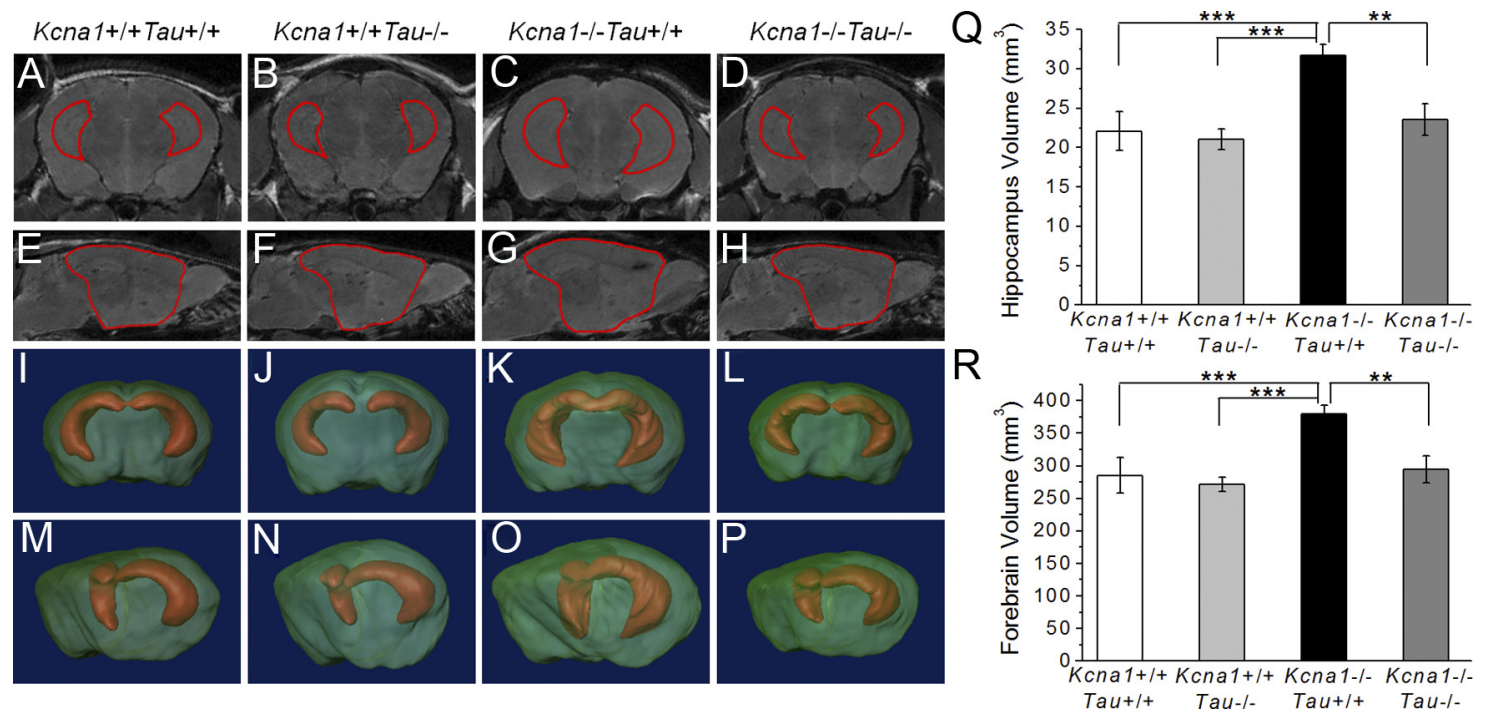

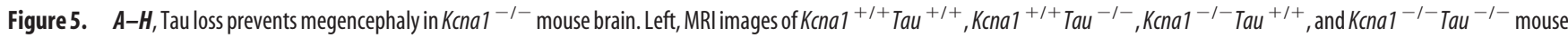
brain were manually segmented and hippocampus $(\boldsymbol{A}-\boldsymbol{D})$ and forebrain $(\boldsymbol{E}-\boldsymbol{H})$ borders drawn to allow $3 \mathrm{D}$ reconstruction. $\boldsymbol{I}-\boldsymbol{P}, 3 \mathrm{D}$ reconstructions shown in both coronal $(\boldsymbol{I}-\boldsymbol{L})$ and partial sagittal $(\boldsymbol{M}-\boldsymbol{P})$ views demonstrate the enlargement of the hippocampus and forebrain in $\mathrm{Knal}^{-1-} \mathrm{Tau}^{+/+}(\boldsymbol{K}, \mathbf{0})$ mice relative to other genotypes. $\mathbf{Q}, \boldsymbol{R}, \mathbf{Q u a n t i f i c a t i o n}$ of hippocampus $(\boldsymbol{Q})$ and forebrain $(\boldsymbol{R})$ volume in double-mutant mice. $\mathrm{KCna}^{-/-} \mathrm{Tau}^{-/-}$mice had significantly decreased hippocampus and forebrain volume compared with the megencephalic Kcna1 ${ }^{-/-} \mathrm{Tau}^{+/+}$. Loss of tau in $\mathrm{KCna1}^{-/-}$mice decreased hippocampus and forebrain volume to wild-type levels. ${ }^{* *} p=0.003,{ }^{* * *} p=0.001$; one-way ANOVA; $n=3$; error bars represent SD.

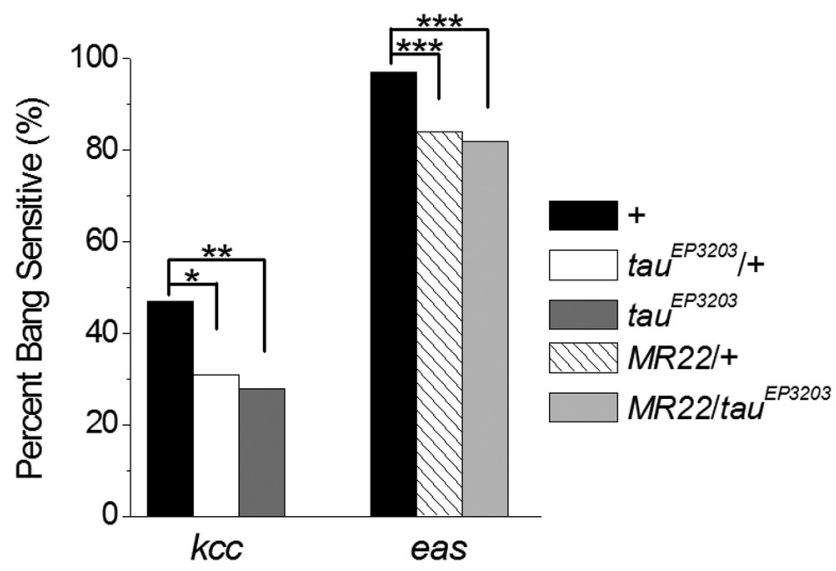

Figure 6. Tau reduction significantly decreases hyperexcitability in bang-sensitive Drosophila mutants kcc and eas. Quantification of the percentage of flies that were bang sensitive in response to a vortex stimulus. Decreasing tau dosage by the $\operatorname{tau}^{E P 3203}$ allele significantly decreased bang sensitivity in $k c c$ mutants by $34 \%$ in $k c c ; t a u^{E P 3203} /+$ and $40 \%$ in $k c c ; t a u^{E P 3203}$ compared with $k c c$ flies with wild-type tau $(n \geq 87)$. Decreasing tau by the deficiency allele MR22 significantly decreased bang sensitivity in eas mutants by $13 \%$ (eas;MR22/+) and $15 \%$ (eas;MR22/tau ${ }^{E P 3203}$ ) compared with eas flies with wild-type tau ( $\left.\mathrm{n} \geq 98\right) .{ }^{*} p<0.05$, ${ }^{* *} p<$

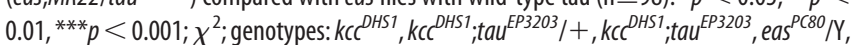
eas $^{P C 80} / Y ; D f(3 R) M R 22 /+$, eas ${ }^{P C 80} / Y ; D f(3 R) M R 22 / \operatorname{tau}^{E P 3203}$.

wild type at 12 weeks of age. A previous report also shows that $\mathrm{Tau}^{-1-}$ mice exhibit wild-type brain size at 6 months of age, although beyond one year brain atrophy is observed (Lei et al., 2012). Based on these lines of evidence, early rescue of megencephaly in our model is likely due to the decreased seizures and hyperexcitability in developing $\mathrm{KCnal}^{-/-} \mathrm{Tau}^{-1-}$ mice.

Tau reduction decreases hyperexcitability in Drosophila seizure models

We have further shown that partial tau reduction is sufficient to significantly ameliorate the BS phenotype in two different Drosophila hyperexcitability mutants. Kcc encodes the fly $\mathrm{K}^{+} / \mathrm{Cl}^{-}$ cotransporter, and a partial loss-of-function allele increases seizure susceptibility due to reduction of the $\mathrm{Cl}^{-}$gradient and impaired GABAergic transmission (Hekmat-Scafe et al., 2010). Loss of KCC2, the mammalian homolog of $k c c$, in mice also results in seizures and hyperexcitability (Woo et al., 2002). Truncation of the eas gene reduces ethanolamine kinase activity, interfering with metabolism of phosphatidylethanolamine, the predominant membrane lipid, which may alter neuroblast development in the Drosophila mushroom body (Pavlidis et al., 1994; Pascual et al., 2005). The ability of tau reduction to decrease seizure susceptibility in all three mutant models demonstrates that tau is a genetic modifier of hyperexcitability that is not specific to a single pathway or molecular mechanism of excitability.

\section{Is tau a possible therapeutic target in epilepsy?}

While our results reflect the absence of tau during nervous system development rather than reversal of a preexisting seizure disorder, the robust effect of even partial genetic tau reduction on hyperexcitability phenotypes supports future examination of pharmacological tau reduction as a possible strategy for early disease modification in epilepsy. Although the potentially adverse effects of tau loss have not been fully evaluated, they so far appear to be limited. Despite delays in neuronal migration and process length in culture, synaptic connectivity in $\mathrm{Tau}^{-1-}$ mouse brain is not apparently altered, as evident by normal synaptophysin and GAP-43 distribution as well as normal GFAP staining patterns (Dawson et al., 2001). In addition, we saw no visible differences in cellular lamination patterns in cresyl violet stained $\mathrm{Tau}^{-1-}$ sections. $\mathrm{Tau}^{-1-}$ mice also reportedly show no learning or memory deficits, as well as relatively normal hippocampal electrophysiological properties through 6 months of age (Ikegami et al., 2000; Roberson et al., 2007; Dawson et al., 2010; Ittner et al., 2010; Roberson et al., 2011; Lei et al., 2012). Tau ${ }^{-1-}$ mice do show increased sIPSCs in dentate granule cells and less network bursting in disinhibited hippocampal slices, providing one candidate mechanism for decreasing network hyperexcitability in the brain (Morris et al., 2011; Roberson et al., 2011). Tau loss may also be neuroprotective, since knockout leads to defective postsynaptic localization of fyn kinase and decreased excito- 
toxic damage in response to neuronal activity (Ittner et al., 2010). Some deleterious consequences of early and complete genetic tau loss were found in aged, 12-month-old $\mathrm{Tau}^{-1-}$ mice including brain atrophy, iron accumulation, substantia nigra cell loss, and axonal spheroids. (Dawson et al., 2010; Lei et al., 2012).

We have shown that tau loss decreases excitability in the non$\mathrm{AD}$, epileptic brain. Interestingly, even heterozygous reduction of tau was sufficient to significantly lower seizure frequency, suggesting the potential of tau regulation as a therapeutic target. This is supported by evidence in $\mathrm{AD}$ mouse models where heterozygous tau loss decreases hyperexcitability and also improves cognition (Roberson et al., 2007, 2011; Ittner et al., 2010). Importantly, to our knowledge, no neurological deficits have been shown in $\mathrm{Tau}^{+/-}$mice at any age studied (Ikegami et al., 2000; Roberson et al., 2007, 2011). Additionally, pharmacological tau reduction by methylene blue, which reduces soluble tau and improves cognition in transgenic tau mice, does not impair Morris Water Maze memory recall in wild-type mice (O'Leary et al., 2010). These results suggest that while complete loss of tau throughout life is not inconsequential, there are potential therapeutic benefits of decreasing tau at an early stage of epileptogenesis.

Overall, these data reflect the genomic absence of tau throughout brain development rather than the reversal of an established seizure disorder. Further studies using developmentally delayed reduction of tau levels will be necessary to distinguish whether the observed changes in hyperexcitability are due to early, synaptic reorganization of the brain or to an ongoing intrinsic regulatory role of tau in adult neuronal firing properties and synaptic transmission.

\section{References}

Adelman JP, Bond CT, Pessia M, Maylie J (1995) Episodic ataxia results from voltage-dependent potassium channels with altered functions. Neuron 15:1449-1454. CrossRef Medline

Almgren M, Persson AS, Fenghua C, Witgen BM, Schalling M, Nyengaard JR, Lavebratt C (2007) Lack of potassium channel induces proliferation and survival causing increased neurogenesis and twofold hippocampus enlargement. Hippocampus 17:292-304. CrossRef Medline

Andrews-Zwilling Y, Bien-Ly N, Xu Q, Li G, Bernardo A, Yoon SY, Zwilling D, Yan TX, Chen L, Huang Y (2010) Apolipoprotein E4 causes age- and Tau-dependent impairment of GABAergic interneurons, leading to learning and memory deficits in mice. J Neurosci 30:13707-13717. CrossRef Medline

Augustinack JC, Schneider A, Mandelkow EM, Hyman BT (2002) Specific tau phosphorylation sites correlate with severity of neuronal cytopathology in Alzheimer's disease. Acta Neuropathol 103:26-35. CrossRef Medline

Buerger K, Teipel SJ, Zinkowski R, Blennow K, Arai H, Engel R, HofmannKiefer K, McCulloch C, Ptok U, Heun R, Andreasen N, DeBernardis J, Kerkman D, Moeller H, Davies P, Hampel H (2002) CSF tau protein phosphorylated at threonine 231 correlates with cognitive decline in MCI subjects. Neurology 59:627-629. CrossRef Medline

Cirrito JR, Yamada KA, Finn MB, Sloviter RS, Bales KR, May PC, Schoepp DD, Paul SM, Mennerick S, Holtzman DM (2005) Synaptic activity regulates interstitial fluid amyloid-beta levels in vivo. Neuron 48:913-922. CrossRef Medline

Crespo-Biel N, Canudas AM, Camins A, Pallàs M (2007) Kainate induces AKT, ERK and cdk5/GSK3beta pathway deregulation, phosphorylates tau protein in mouse hippocampus. Neurochem Int 50:435-442. CrossRef Medline

Dawson HN, Cantillana V, Jansen M, Wang H, Vitek MP, Wilcock DM, Lynch JR, Laskowitz DT (2010) Loss of tau elicits axonal degeneration in a mouse model of Alzheimer's disease. Neuroscience 169:516-531. CrossRef Medline

Dawson HN, Ferreira A, Eyster MV, Ghoshal N, Binder L, Vitek MP (2001) Inhibition of neuronal maturation in primary hippocampal neurons from tau deficient mice. J Cell Sci 114:1179-1187. Medline

Dixit R, Ross JL, Goldman YE, Holzbaur EL (2008) Differential regulation of dynein and kinesin motor proteins by tau. Science 319:1086-1089. CrossRef Medline

Doerflinger H, Benton R, Shulman JM, St Johnston D (2003) The role of PAR-1 in regulating the polarised microtubule cytoskeleton in the Drosophila follicular epithelium. Development 130:3965-3975. CrossRef Medline

Glasscock E, Qian J, Yoo JW, Noebels JL (2007) Masking epilepsy by combining two epilepsy genes. Nat Neurosci 10:1554-1558. CrossRef Medline

Glasscock E, Yoo JW, Chen TT, Klassen TL, Noebels JL (2010) Kv1.1 potassium channel deficiency reveals brain-driven cardiac dysfunction as a candidate mechanism for sudden unexplained death in epilepsy. J Neurosci 30:5167-5175. CrossRef Medline

Glasscock E, Qian J, Kole MJ, Noebels JL (2012) Transcompartmental reversal of single fiber hyperexcitability in juxtaparanodal Kv1.1-deficient vagus nerve axons by activation of nodal KCNQ channels. J Physiol 590: 3913-3926. CrossRef Medline

Goedert M, Spillantini MG (2006) A century of Alzheimer's disease. Science 314:777-781. CrossRef Medline

Hekmat-Scafe DS, Lundy MY, Ranga R, Tanouye MA (2006) Mutations in the $\mathrm{K}+/ \mathrm{Cl}$ - cotransporter gene kazachoc $(\mathrm{kcc})$ increase seizure susceptibility in Drosophila. J Neurosci 26:8943-8954. CrossRef Medline

Hekmat-Scafe DS, Mercado A, Fajilan AA, Lee AW, Hsu R, Mount DB, Tanouye MA (2010) Seizure sensitivity is ameliorated by targeted expression of $\mathrm{K}+-\mathrm{Cl}$ - cotransporter function in the mushroom body of the Drosophila brain. Genetics 184:171-183. CrossRef Medline

Hunter JM, Cirrito JR, Restivo JL, Kinley RD, Sullivan PM, Holtzman DM, Koger D, Delong C, Lin S, Zhao L, Liu F, Bales K, Paul SM (2012) Emergence of a seizure phenotype in aged apolipoprotein epsilon 4 targeted replacement mice. Brain Res 1467:120-132. CrossRef Medline

Ikegami S, Harada A, Hirokawa N (2000) Muscle weakness, hyperactivity, and impairment in fear conditioning in tau-deficient mice. Neurosci Lett 279:129-132. CrossRef Medline

Ittner LM, Ke YD, Delerue F, Bi M, Gladbach A, van Eersel J, Wölfing H, Chieng BC, Christie MJ, Napier IA, Eckert A, Staufenbiel M, Hardeman E, Götz J (2010) Dendritic function of tau mediates amyloid-beta toxicity in Alzheimer's disease mouse models. Cell 142:387-397. CrossRef Medline

Kawarabayashi T, Younkin LH, Saido TC, Shoji M, Ashe KH, Younkin SG (2001) Age-dependent changes in brain, CSF, and plasma amyloid (beta) protein in the $\mathrm{Tg} 2576$ transgenic mouse model of Alzheimer's disease. J Neurosci 21:372-381. Medline

Kuebler D, Tanouye MA (2000) Modifications of seizure susceptibility in Drosophila. J Neurophysiol 83:998-1009. Medline

Kuebler D, Zhang H, Ren X, Tanouye MA (2001) Genetic suppression of seizure susceptibility in Drosophila. J Neurophysiol 86:1211-1225. Medline

Lavebratt C, Trifunovski A, Persson AS, Wang FH, Klason T, Ohman I, Josephsson A, Olson L, Spenger C, Schalling M (2006) Carbamazepine protects against megencephaly and abnormal expression of BDNF and Nogo signaling components in the mceph/mceph mouse. Neurobiol Dis 24:374-383. CrossRef Medline

Lei P, Ayton S, Finkelstein DI, Spoerri L, Ciccotosto GD, Wright DK, Wong BX, Adlard PA, Cherny RA, Lam LQ, Roberts BR, Volitakis I, Egan GF, McLean CA, Cappai R, Duce JA, Bush AI (2012) Tau deficiency induces parkinsonism with dementia by impairing APP-mediated iron export. Nat Med 18:291-295. CrossRef Medline

Li G, Bien-Ly N, Andrews-Zwilling Y, Xu Q, Bernardo A, Ring K, Halabisky B, Deng C, Mahley RW, Huang Y (2009) GABAergic interneuron dysfunction impairs hippocampal neurogenesis in adult apolipoprotein E4 knockin mice. Cell Stem Cell 5:634-645. CrossRef Medline

Liang Z, Liu F, Iqbal K, Grundke-Iqbal I, Gong CX (2009) Dysregulation of tau phosphorylation in mouse brain during excitotoxic damage. J Alzheimers Dis 17:531-539. Medline

Liguori R, Avoni P, Baruzzi A, Di Stasi V, Montagna P (2001) Familial continuous motor unit activity and epilepsy. Muscle Nerve 24:630-633. CrossRef Medline

Lopantsev V, Tempel BL, Schwartzkroin PA (2003) Hyperexcitability of CA3 pyramidal cells in mice lacking the potassium channel subunit Kv1.1. Epilepsia 44:1506-1512. CrossRef Medline

Morris M, Maeda S, Vossel K, Mucke L (2011) The many faces of tau. Neuron 70:410-426. CrossRef Medline 
O’Leary JC 3rd, Li Q, Marinec P, Blair LJ, Congdon EE, Johnson AG, Jinwal UK, Koren J 3rd, Jones JR, Kraft C, Peters M, Abisambra JF, Duff KE, Weeber EJ, Gestwicki JE, Dickey CA (2010) Phenothiazine-mediated rescue of cognition in tau transgenic mice requires neuroprotection and reduced soluble tau burden. Mol Neurodegener 5:45. CrossRef Medline

Parker L, Howlett IC, Rusan ZM, Tanouye MA (2011) Seizure and epilepsy: studies of seizure disorders in Drosophila. Int Rev Neurobiol 99:1-21. CrossRef Medline

Pascual A, Chaminade M, Préat T (2005) Ethanolamine kinase controls neuroblast divisions in Drosophila mushroom bodies. Dev Biol 280:177186. CrossRef Medline

Pavlidis P, Ramaswami M, Tanouye MA (1994) The Drosophila easily shocked gene: a mutation in a phospholipid synthetic pathway causes seizure, neuronal failure, and paralysis. Cell 79:23-33. CrossRef Medline

Persson AS, Westman E, Wang FH, Khan FH, Spenger C, Lavebratt C (2007) Kv1.1 null mice have enlarged hippocampus and ventral cortex. BMC Neurosci 8:10. CrossRef Medline

Roberson E, Scearce-Levie K, Palop J, Yan F, Cheng I, Wu T, Gerstein H, Yu G, Mucke L (2007) Reducing endogenous tau ameliorates amyloid betainduced deficits in an Alzheimer's disease mouse model. Science 316: 750-754. CrossRef Medline

Roberson ED, Halabisky B, Yoo JW, Yao J, Chin J, Yan F, Wu T, Hamto P, Devidze N, Yu GQ, Palop JJ, Noebels JL, Mucke L (2011) Amyloid- $\beta$ / Fyn-induced synaptic, network, and cognitive impairments depend on tau levels in multiple mouse models of Alzheimer's disease. J Neurosci 31:700-711. CrossRef Medline

Shipton OA, Leitz JR, Dworzak J, Acton CE, Tunbridge EM, Denk F, Dawson HN, Vitek MP, Wade-Martins R, Paulsen O, Vargas-Caballero M (2011)
Tau protein is required for amyloid \{beta\}-induced impairment of hippocampal long-term potentiation. J Neurosci 31:1688-1692. CrossRef Medline

Smart SL, Lopantsev V, Zhang CL, Robbins CA, Wang H, Chiu SY, Schwartzkroin PA, Messing A, Tempel BL (1998) Deletion of the K(V)1.1 potassium channel causes epilepsy in mice. Neuron 20:809-819. CrossRef Medline

Song J, Tanouye MA (2008) From bench to drug: human seizure modeling using Drosophila. Prog Neurobiol 84:182-191. CrossRef Medline

Vossel KA, Zhang K, Brodbeck J, Daub AC, Sharma P, Finkbeiner S, Cui B, Mucke L (2010) Tau reduction prevents Abeta-induced defects in axonal transport. Science 330:198. CrossRef Medline

Wang JZ, Liu F (2008) Microtubule-associated protein tau in development, degeneration and protection of neurons. Prog Neurobiol 85:148-175. CrossRef Medline

Woo NS, Lu J, England R, McClellan R, Dufour S, Mount DB, Deutch AY, Lovinger DM, Delpire E (2002) Hyperexcitability and epilepsy associated with disruption of the mouse neuronal-specific K-Cl cotransporter gene. Hippocampus 12:258-268. CrossRef Medline

Yang SB, Mclemore KD, Tasic B, Luo L, Jan YN, Jan LY (2012) Kv1.1dependent control of hippocampal neuron number as revealed by mosaic analysis with double markers (MADM). J Physiol 590:2645-2658. Medline

Zuberi SM, Eunson LH, Spauschus A, De Silva R, Tolmie J, Wood NW, McWilliam RC, Stephenson JB, Stephenson JP, Kullmann DM, Hanna MG (1999) A novel mutation in the human voltage-gated potassium channel gene (Kv1.1) associates with episodic ataxia type 1 and sometimes with partial epilepsy. Brain 122:817-825. CrossRef Medline 